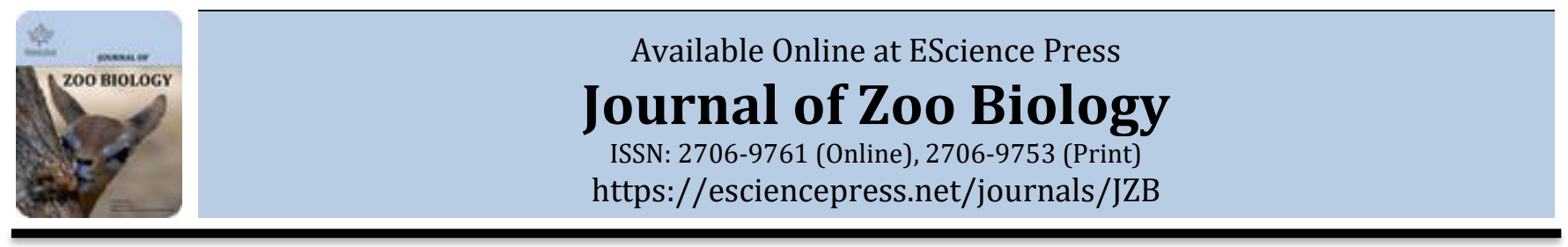

\title{
PRELIMINARY EVALUATION OF SEMINAL PLASMA PROTEINS AND IMMUNOREACTIVITY OF NERVE GROWTH FACTOR AS INDICATIVE OF AN OVULATION INDUCING FACTOR IN ODONTOCETES
}

\author{
aDon R. Bergfelt*, aJason L. Blum, bJill R. Ratner, cMarcelo H. Ratto, dJustin K. O'Brien, dTodd R. Robeck \\ a Department of Biomedical Sciences, Ross University School of Veterinary Medicine, Basseterre, West Indies. \\ ${ }^{b}$ Department of Environmental Medicine, New York University School of Medicine, Tuxedo, United States. \\ c Faculty of Veterinary Sciences, Universidad Austral de Chile, Valdivia, Chile. \\ d SeaWorld and Busch Gardens Species Preservation Laboratory, San Diego, United States.
}

*Corresponding Author Email: dbergfelt@rossvet.edu.kn

\section{A B S T R A C T}

In the seminal plasma of terrestrial mammalian species known as induced (e.g., camels) and spontaneous (e.g., cattle) ovulators, an ovulation-inducing factor (OIF) with a protein structure similar to beta-nerve growth factor ( $\beta$-NGF) has been identified. Detection of an OIF/NGF in the seminal plasma of cetaceans would have both basic and applied implications in reproductive biology and conservation management programs. A preliminary evaluation was conducted to characterize the distribution and abundance of seminal plasma proteins in aquarium-based belugas and a Pacific white-sided and bottlenose dolphin. Initially, SDS-PAGE was used with $50 \mu \mathrm{g}$ of total protein for separation; thereafter, Western immunoblot was used with anti-NGF. In addition to odontocete seminal plasma, a purified fraction of llama seminal plasma (100 ng protein) and an extract of mouse brain (20 $\mu \mathrm{g}$ total protein) were included as positive controls for NGF. Within the two belugas, visual inspection of the protein bands indicated similar distribution and intensity. However, among the belugas and Pacific white-sided and bottlenose dolphins there was more diversity than similarity in the distribution and abundance of seminal plasma proteins. While immunoreactivity of NGF was distinctly evident in the llama and mouse positive controls, there was no visual reactivity in any of the odontocete samples. These preliminary results provide novel information indicating more homogeneity within and heterogeneity among seminal plasma proteins of ondentocetes. Although NGF was not immunologically detected, future studies are required to address the apparent limitations of immuno-detection of NGF, especially if the post-translational form of $\beta$-NGF is in low abundance in the seminal plasma of belugas and Pacific white-sided and bottlenose dolphins.

Keywords: odontocetes, seminal plasma, ovulation-inducing factor, nerve growth factor.

\section{INTRODUCTION}

It is well accepted that seminal plasma facilitates delivery and provides a nutritive environment for sperm (Poiani 2006); however, recent studies in a wide variety of species have provided evidence that seminal plasma and its proteinaceous constituents play a much broader role in fertility (Druarta et al., 2013, McGraw et al., 2015, Bromfield 2016). Compared to multiple other mammalian species (Mogielnicka-Brzozowska and Kordan 2011), knowledge of the constituents of seminal plasma in cetaceans is nil. Apart from a single study (O'Brien et al., 2008) that describes the clinical biochemistry of seminal plasma from belugas
(Delphinapterus leucas), the proteinaceous constituency of seminal plasma in cetaceans is not known.

It remains equivocal if all cetaceans are spontaneous or induced ovulators or some proportion of both (i.e., facultative). Historically, bottlenose dolphins (Tursiops truncatus), La Plata River dolphins (Pontoporia blainvillei), and belugas were reported to be coitusinduced ovulators (Kleinenberg et al., 1964, Harrison and Ridgeway 1971, Harrison et al., 1972, Harrison 1977; Harrison et al., 1981, Kirby and Ridgeway 1984, Yoshioka et al., 1986, Schroeder 1990). Apart from the beluga, more recent studies have provided additional evidence that the bottlenose dolphin, common dolphin (Delphinus delphis), 
false killer whale (Pseudorca crassidens), killer whale (Orcinus orca), Pacific white-sided dolphin (Lagenorhynchus obliquidens), Risso dolphin (Grampus griseus), and spotted dolphin (Stenella attenuata) are spontaneous ovulators (Benirshcke et al., 1980, SawyerSteffan et al., 1983, Kirby and Ridgeway 1984, Robeck et al., 1993, Combelles 1995, Atkinson et al., 1999, Robeck et al., 2009). Recent longitudinal ultrasonic imaging and hormonal data have indicated that adult female belugas may be facultative-induced ovulators (Steinman et al., 2012). In the presence of a male, belugas ovulated $85 \%$ of the time, whereas, in the absence of a breeding male, belugas spontaneously ovulated in $26 \%$ of estrous cycles. Combined, past and more recent data support the concept that the beluga may be a facultative-induced ovulator; however, additional evidence is required for confirmation.

In general, ovulation in mammals involves a neuroendocrine signaling mechanism between the reproductive organs and brain (Kauffman and Rissman 2006). Regardless of the mode of ovulation, hypothalamic GnRH secretion is necessary to stimulate the preovulatory LH surge from the anterior pituitary gland that signals ovulation of one or more dominant ovarian follicles. In spontaneous ovulators (e.g., humans, rats, cattle), increased estrogen production by one or more pre-ovulatory follicles appears to be the primary stimulus that triggers GnRH secretion, whereas, in induced ovulators (e.g., camels, rabbits, ferrets), physical vaginocervical contact associated with copulation during estrus is thought to be the primary trigger for GnRH secretion. Traditionally, the stimulus for induced ovulation has been considered to be physical or tactile in nature (Jochle 1973); however, recent evidence indicates that the stimulus may be a biochemical constituent of semen (review Adams et al., 2013, Allali et al., 2017). The first direct evidence of semen-induced ovulation emerged more than 30 years ago from studies with Bactrian camels (Camelus bactrianus), which are known induced ovulators. It was demonstrated that, regardless of the route of conspecific administration, camel seminal plasma given intravaginal (Chen et al., 1985; Xu et al., 1985), intramuscular or intrauterine (Pan et al., 1992) induced ovulations. More recent studies (Adams et al., 2013) in other known induced ovulators have indicated that a single intramuscular dose of llama or alpaca seminal plasma induced ovulation in $>90 \%$ of females of the respective species compared to $0 \%$ in those given saline (Adams et al., 2005). Comparatively, intramuscular administration of seminal plasma from spontaneously ovulating cattle (Ratto et al., 2006), horses and pigs (Bogle et al., 2011) was also able to induce ovulation albeit at a lower rate in $29 \%$ of llamas with $0 \%$ ovulations in saline controls.

Biochemical isolation and purification of an ovulationinducing factor (OIF) in llama seminal plasma resulted in the identification of a protein with a peptide sequence and structure $(14 \mathrm{kDa})$ identical to beta nerve growth factor ( $\beta$-NGF, Ratto et al., 2012). The physiologicical effect of the purified OIF/NGF-like substance found in llama seminal plasma was evaluated using a single intramuscular injection in estrus-synchronized llamas. Results indicated a post-treatment pre-ovulatory LH surge, ovulation, and CL formation in $91 \%$ of the treated llamas compared to $0 \%$ of the saline controls (Ratto et al., 2012).

While the nature and functional role of NGF associated with development, growth, and reproduction is well documented in humans and various laboratory (Wiesmann and de Vos 2001, Aloe et al., 2013, Seidel et al., 2013), domestic, and a few exotic terrestrial mammals (Adams et al., 2013, Allali et al., 2017), no published documentation was found on NGF in aquatic marine mammals. Detection, identification, and quantification of NGF as indicative of an OIF in the seminal plasma of odontocetes can provide additional evidence to clarify if the beluga is a facultative-induced ovulator. More broadly, detection of seminal plasma NGF can have basic and applied implications in reproductive management and conservation biology among cetaceans.

The present study was designed as a preliminary evaluation to characterize the basic distribution and abundance of seminal plasma proteins and immunoreactivity of NGF in several odontocetes belugas, a Pacific white-sided dolphin, and a bottlenose dolphin.

\section{MATERIALS AND METHODS}

Odontocetes and management: The present study involved a retrospective analysis of archived sperm-free seminal plasma collected from two belugas, a Pacific white-sided dolphin, and a bottlenose dolphin during routine animal husbandry exams from 2014 to 2015 at SeaWorld Parks and Entertainment (San Diego, CA; San Antonio, TX; Orlando, FL, USA). The belugas were born August 8, 1992 (Beluga A, 22 yrs at the time of semen collection) and July 13, 2003 (Beluga B, 11 yrs), Pacific 
white-sided dolphin born Sept 8, 2003 (11 yrs), and bottlenose dolphin born Aug 16, 1989 (26 yrs). Apart from the Pacific white-sided dolphin, the belugas and bottlenose dolphin are proven sires with live calves.

Animals were managed in compliance with the US Animal Welfare Act and by the Standards and Guidelines of the Alliance of Marine Mammal Parks and Aquariums. Practices and procedures associated with the study were reviewed and approved by SeaWorld's Animal Care and Use Committee. Feeding consisted of individual diets of frozen-thawed whole fish (herring, Clupea harengus; capelin, Mallotus villosus; Columbia River smelt, Thaleichthys pacificus) at approximately 4 to $5 \%$ of body weight per day.

Collection and processing of seminal plasma: Semen samples were collected from each animal using behavioral conditioning as previously reported (O'Brien et al., 2008, Robeck and O'Brien 2004, Robeck et al., 2009). Beluga samples were collected in Sept and Oct 2014, Pacific white-sided dolphin in Sept 2014, and bottlenose dolphin in June 2015. For Beluga B, semen samples were collected on Sept 25 and 27, and in the morning and afternoon on Sept 27 to initially assess changes in seminal plasma proteins within and between days. Once collected, ejaculates were held at ambient temperature $\left(21^{\circ} \mathrm{C}\right)$ and processed within $30 \mathrm{~min}$. Only semen samples which had normal osmolarity $(\leq 370 \mathrm{mOsm} / \mathrm{kg}$ for belugas, $<350$ $\mathrm{mOsm} / \mathrm{kg}$ for Pacific white-sided and bottlenose dolphins), sperm concentration ( $>100 \times 10^{6}$ sperm $/ \mathrm{mL}$ for belugas and $>400 \times 10^{6} \mathrm{sperm} / \mathrm{mL}$ for dolphins), and percent progressively motile $(>80 \%)$ and live $(>90 \%$ intact plasma membrane) sperm were considered for further processing. Seminal plasma was isolated from spermatozoa by centrifugation $(2000 \mathrm{xg}$ for $10 \mathrm{~min}$ at $11^{\circ} \mathrm{C}$ ). A seminal sample was observed under microscope (200x magnification) to confirm absence of spermatozoa. Thereafter, $2 \mathrm{~mL}$ aliquots were placed in cryotubes (Nunc, Rochester, NY, USA), flash frozen in liquid nitrogen, and stored at $-80^{\circ} \mathrm{C}$ until analysis.

Positive controls for NGF: Purified llama seminal plasma (Ratto et al., 2012) and mouse brain extract (Katoh-Semba et al., 1989, Katoh-Semba et al., 1994) were used as positive controls for $\beta$-NGF. Purified llama seminal plasma was prepared as previously described (Ratto et al., 2012) and a crude extract of mouse brain was prepared as follows. Briefly, the brain from a retired male breeder mouse (strain $\mathrm{B}_{6} \mathrm{C}_{3} \mathrm{~F}_{1}$ ) was collected after euthanasia via intraperitoneal injection of sodium pentobarbital $(150 \mathrm{mg} / \mathrm{kg})$ and exsanguinated via the descending aorta in accord with an approved IACUC protocol (NYU School of Medicine). After the skull was opened, the entire brain was placed in $5 \mathrm{~mL}$ of radioimmunoprecipitation assay (RIPA) buffer (100 mM sodium phosphate, $\mathrm{pH} 7.2,10 \mathrm{mM}$ each of EGTA and sodium fluoride, $12.5 \mathrm{mM}$ EDTA, $1 \%$ each of sodium deoxycholate and Triton X-100, $0.1 \%$ sodium dodecylsulfate, and 200 Kallikrein units of aprotinin) containing a protease inhibitor cocktail (cOmplete Mini; Roche, Mannheim, Germany). Thereafter, the brain was homogenized with a tissuemizer powered hand homogenizer for $2 \mathrm{~min}$ in $30 \mathrm{sec}$ pulses on ice followed by centrifugation at $8000 \mathrm{xg}$ for $10 \mathrm{~min}$ at $4^{\circ} \mathrm{C}$. Supernatants were aliquoted and stored at $-80^{\circ} \mathrm{C}$ until analysis.

Total protein and separation (SDS-PAGE): Total protein concentrations in the cetacean seminal plasma samples and the purified llama sample were determined using the Bradford protein assay (Biorad; Hercules, CA, USA) with bovine serum albumin (Sigma, St. Louis, MO, USA) as standard. Total protein concentration of mouse brain extract was determined using the BCA protein assay (Pierce Biotechnology, Rockford, IL, USA) with bovine serum albumin (Sigma, St. Louis, MO, USA) as the standard.

Sodium dodecyl sulfate polyacrylamide gel electrophoresis (SDS-PAGE, Laemmli 1970) was used to initially separate odontocete seminal plasma proteins. Briefly, seminal plasma samples (50 ug of total protein) from each animal and time period were combined with $4 \mathrm{x}$ Laemmli buffer (final $1 \mathrm{x}$ ) containing 20\% $\beta$ mercaptoethanol, heated to $95^{\circ} \mathrm{C}$ for $5 \mathrm{~min}$, and cooled to room temperature. For protein separation, individual samples were loaded into six separate lanes of the SDSPAGE gel (12.5\%). The gel was stained with Coomassie brilliant blue (50\% methanol, $10 \%$ acetic acid, $40 \%$ water, $0.05 \%$ brilliant blue R250) for $1 \mathrm{~h}$ at room temperature and destained (staining buffer without R250) at room temperature overnight to visualize the protein bands. After destaining, the gel was imaged using a Gel Doc XR+ with Image Lab software (Biorad). A range of molecular weight markers (10 ?L, Biorad) were used to estimate the molecular weights of the protein bands.

Western immunoblot analysis of NGF: Protein separation of odontocete seminal plasma samples including purified llama seminal plasma (100 ng) and an extract of mouse brain (20 $\mu \mathrm{g}$ of total protein) as positive controls was done by SDS-PAGE as described in the 
previous section. Following gel separation, proteins were transferred to a nitrocellulose membrane using Towbin buffer and, thereafter, stained with Ponceau-S $0.1 \%$ Ponceau-S in 5\% acetic acid) and imaged using the same process described in the previous section. Prior to immunoblot analysis, the membrane was destained in Tris-buffered saline and blocked for $1 \mathrm{~h}$ in Tris-buffered saline containing $0.1 \%$ Tween-20 (TBST) and 5\% Carnation $\AA$ nonfat dry milk. After blocking, the membrane was incubated overnight at $4^{\circ} \mathrm{C}$ in blocking buffer containing 1:1000 dilution of rabbit anti-NGF (polyclonal NGF antibody [H-20]: sc-548; Santa Cruz Biotechnology, Dallas, TX, USA) directed against $\beta$-NGF. Subsequently, the blot was washed in TBST and incubated for $1 \mathrm{~h}$ at room temperature with gentle rocking in 1:5000 dilution of goat anti-rabbit antibody conjugated to horseradish peroxidase (Pierce Biotechnology) in blocking buffer. Lastly, the blot was rinsed in TBST and incubated in detection reagents as described by the manufacturer and exposed to film.

\section{RESULTS}

SDS-PAGE analysis of seminal plasma from four odontocetes with molecular weight distribution and abundance of various proteins is shown in Figure 1. Based on visual inspection of the gel, there are distinct and less distinct bands of proteins as indicated that appear similar within species (belugas) but different among species.

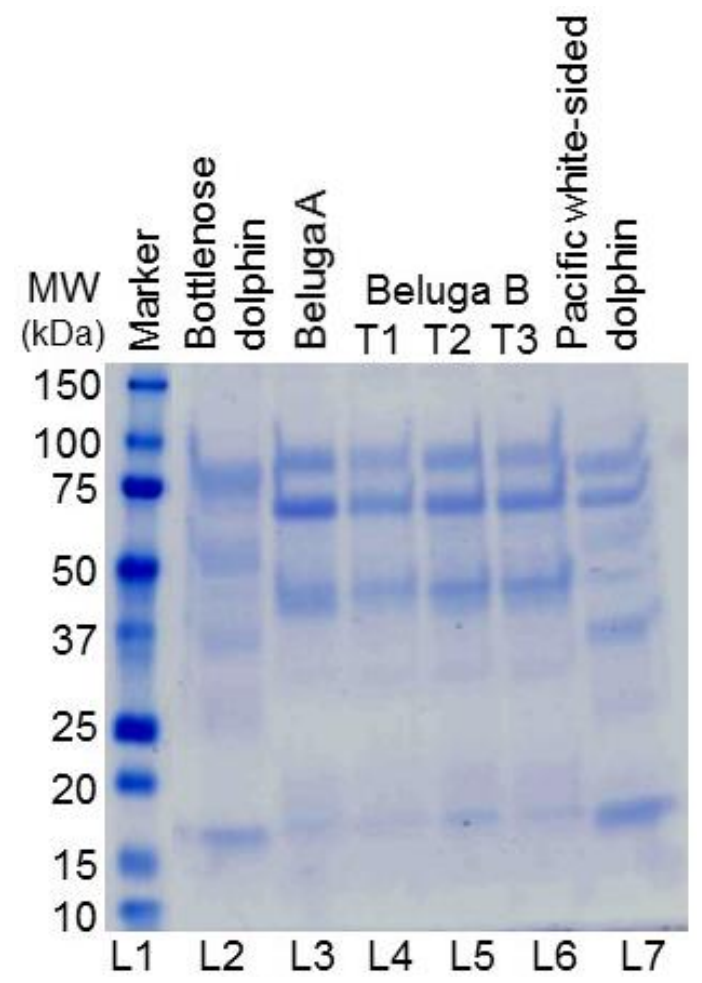

Figure 1. Protein separation of odontocete seminal plasma (50 ug total protein) with SDS-PAGE and Coomassie blue stain relative to a molecular weight (MW) marker in Lane 1. Lane $2=$ Bottlenose dolphin; Lane $3=$ Beluga A; Lane $4=$ Beluga B (T1=collection Sept 25); Lane 5 = Beluga B (T2=collection Sept 27, morning hour); Lane 6 = Beluga B (T3=collection Sept 27, afternoon hour); Lane 7 = Pacific white-sided dolphin.

Western immunoblot analysis of NGF in odontocete seminal plasma relative to purified llama seminal plasma and an extract of mouse brain as positive controls is shown in Figure 2. Of the 3 timed seminal plasma samples from Beluga B, only the sample collected on the morning of Sept 27 was used since there appeared to be no visible differences in the number or intensity of the protein bands within and between days (Figure 1). While there were multiple protein bands associated with the extract of mouse brain (Figure 2, Panel a, Lane 4) the protein band expected at about $14 \mathrm{kDa}$ for purified llama OIF/NGF was not distinctly visible (Figure 2, Panel a, Lane 2). Apparently, the amount of highly purified llama OIF/NGF protein (100 ng) loaded on the gel was below the 
sensitivity level for the Ponceau-S stain. Nonetheless, subsequent immunoblotting with anti-NGF resulted in distinct bands of expected molecular weights for the llama and mouse positive control samples but not for any of the odontocete seminal plasma samples (Figure 2, Panel b, Lanes 2 and 4, respectively).

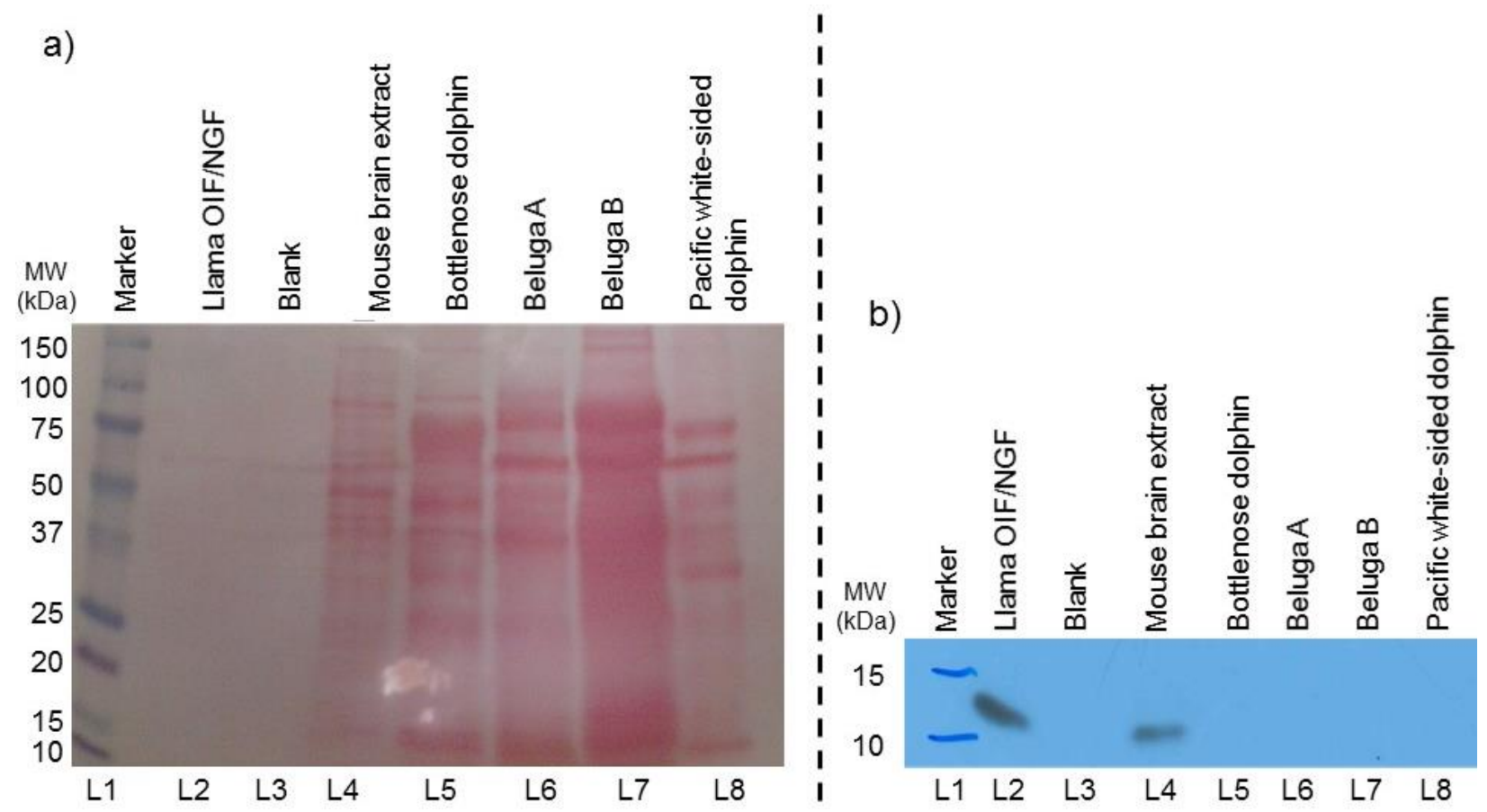

Figure 2. Western immunoblot analysis of seminal plasma (50 ug total protein) in odontocetes relative to purified llama seminal plasma ovulation-inducing factor (OIF/NGF, $100 \mathrm{ng}$ ) in Lane 2 and an extract of mouse brain (20 ug total protein) in Lane 4 as positive controls for $\beta$-NGF. Protein separation followed by transfer to a nitrocellulose membrane and stained with Ponceau-S stain (a) and immunoblot with rabbit anti-NGF at 1:1000 dilution followed by goat antirabbit antibody conjugated to horseradish peroxidase at 1:5000 dilution (b). Beluga B in Lane 7 involved seminal plasma collected Sept 27, morning hour.

\section{DISCUSSION}

Although preliminary, the novelty of the present results indicated multiple bands of proteins of different molecular weights and intensity in the seminal plasma from four odontocetes (belugas, a Pacific white-sided dolphin, and a bottlenose dolphin). Within the two belugas, including different days and times within a day, the distribution and abundance of the seminal plasma proteins appeared visually similar. However, when visually compared among the three species, there were some distinctive differences. Compared to immunoreactivity of $\beta$-NGF in llama seminal plasma and mouse brain extract as positive controls, $\beta$-NGF was not detected in the seminal plasma samples from the belugas or Pacific white-sided and bottlenose dolphins.

In mammals, seminal plasma is considered the fluid portion of semen without spermatozoa (Mogielnicka-
Brzozowska and Kordan 2011, Juyena and Stelletta 2012). While the only source of sperm is the testes, seminal plasma can originate from several sources, including the rete testes, epididymides, accessary sex glands (i.e., ampullary, seminal vesicles, prostate, bulbourethral) as well as exudate of blood plasma (Mann and Lutwak-Mann 1981). In cetaceans, the only major accessary sex gland identified is the prostate (Rommel et al., 2007). Hence, for the odontocetes herein, expected sources of seminal plasma proteins were the rete testes, epididymides, prostate, and blood exudate.

In the present study, SDS-PAGE results characterizing the distribution and abundance of seminal plasma proteins among the four odontocetes indicated similarities and differences among the belugas and Pacific white-sided and bottlenose dolphins. Visually, distribution and abundance of distinct protein bands were observed 
between $90-95 \mathrm{kDa}$ and $65-70 \mathrm{kDa}$ in both the belugas and white-sided dolphin but not in the bottlenose dolphin. Comparatively, only a single distinct protein band was observed at about $80 \mathrm{kDa}$ in the bottlenose. The next level of distinct protein bands were observed at about $48 \mathrm{kDa}$ in the belugas but not in either dolphin species. While apparently absent or indistinct in the beluga whales, prominent protein bands were observed at 38 and $17 \mathrm{kDa}$ in both the Pacific white-sided and bottlenose dolphins. Other less distinct protein bands were observed with some apparent variability among species but, because they were faintly visible, no attempt was made to further characterize them due to speculation. While some noticeable similarities in distribution and abundance of seminal plasma proteins were observed between the beluga and Pacific white-sided dolphin, and Pacific whitesided and bottlenose dolphins, the bottlenose seemed most divergent from the beluga.

Comparison of seminal plasma proteins among several terrestrial mammalian species (boar, bull, ram, buck, stallion, alpaca, camel) using proteomics resulted in considerable divergence among species with only three common proteins (Druart et al., 2013). While genetic diversity likely contributes to the degree of heterogeneity of seminal plasma proteins among species as reported among three different breeds of sheep (Carvajal-Serna1 et al., 2018), other factors such as seasonality reported in rams (Domínguez et al., 2008), buffalo bulls (Sharma et al., 2014), and stallions (Abou-Ahmed et al., 1993) can also have an effect on the proteinaceous constituency of seminal plasma. In the present study, perhaps the degree of heterogeneity of seminal plasma proteins among odontocetes may have been due, in part, to season since the beluga (Steinman et al., 2012) and Pacific white-sided dolphin (Robeck et al., 2009) are seasonally polyestrous. Nonetheless, while the present results require clarification, these preliminary observations in odontocetes appear to support the variability of seminal plasma proteins among species.

The results of Western immunoblot analysis indicated $\beta$ NGF was not detected in the seminal plasma of belugas and Pacific white-sided and bottlenose dolphins. While the NGF antibody was visibly reactive with purified llama seminal plasma and an extract of mouse brain as positive controls, no distinctive immunoreaction was observed for any of the odontocete seminal plasma samples. Immunoreactivity of OIF/NGF in the control samples concurs with that previously reported for purified llama seminal plasma (Ratto et al., 2012) and mouse brain extract (Katoh-Semba et al., 1989, Katoh-Semba et al., 1994). In a comparative study across species (Druart et al., 2013), $\beta$ NGF was detected in the seminal plasma from the ram, stallion, alpaca, and camel using gel-based proteomics (2D LC-MS/MS). However, in the same study, seminal plasma NGF immuno-reactivity was not visibly detected in the ram and stallion using Western immunoblot analysis. The authors did not discuss the basis for the discrepancy between techniques. However, considering that mature, bioactive NGF descends from proteolitic cleavage of a precursor pro-NGF form (Fahnestock et al., $2004 a, b)$, the antibody generated against the posttranslational modified form may have been either of poor specificity or protein abundance was below the level of sensitivity for immuno-detection. In the preset study, the rabbit polyclonal NGF antibody (H-20): sc-548, which is directed against $\beta-\mathrm{NGF}$, was the same as that used to detect seminal plasma NGF in previous studies (Ratto et al., 2012; Druart et al., 2013). Although the basis for not detecting NGF in the seminal plasma of ondentocetes is unknown, future evaluation of ondentocete seminal plasma should consider a broad-based or non-targeted approach. Proteomic analysis casts a wide net that can potentially reveal post-translational changes of the NGF protein and reveal more changes than previously anticipated even in low abundance.

As reviewed (Adams et al., 2013, Allali et al., 2017), OIF/NGF was detected in the seminal plasma of known induced ovulators (e.g., alpaca, llama, camel) as well as known spontaneous ovulators (e.g., cattle, sheep, horse, pig; Ratto et al., 2006, Bogle et al., 2011,Druart et al., 2013). In this regard, administration of seminal plasma from spontaneous vs induced ovulators to llamas, induced ovulation although at a reduced frequency $(29 \%$ vs $>90 \%$ ) in spontaneous ovulators (Ratto et al., 2006, Bogle et al., 2011). Furthermore, $\beta$-NGF was detected in the seminal plasma of both spontaneous and induced ovulators via proteomic analysis. (Druart et al., 2013). Hence, in the present study it was unexpected not to detect $\beta$-NGF in the belugas as proposed facultativeinduced ovulators (Steinman et al., 2012), and, perhaps to a lesser degree, in dolphins as spontaneous ovulators (Benirshcke et al., 1980, Sawyer-Steffan et al., 1983, Kirby and Ridgeway 1984, Combelles 1995, Atkinson et al., 1999, Robeck et al., 2005). The present results did not provide additional evidence to support the beluga as a facultative-induced ovulator. Technical inconsistencies 
(i.e., analytical vs immunological methods; Druart et al., 2013) and potential confounding biological factors (e.g., seasonality; Robeck et al., 2009, Steinman et al., 2012) indicate a need for future studies to utilize alternative approaches (e.g., gel-free proteomics) with appropriate collection times to detect, identify, and quantitate seminal plasma proteins in potentially low abundance in belugas and other odontocetes. The practical implications of characterizing the proteome of seminal plasma proteins has enormous value for selecting a suite of potential biomarkers that can be used to improve semen preservation (Jonakova et al., 2010, MogielnickaBrzozowska and Kordan 2011) or enhance clinical diagnosis/prognosis of reproductive health (Drabovich et al., 2014) for conservation purposes in cetaceans.

\section{CONCLUSION}

The novelty of these preliminary results involving seminal plasma in belugas and Pacific white-sided and bottlenose dolphins using SDS-PAGE provides a rational foundation for more comprehensive studies to evaluate the apparent diversity of proteins in the seminal plasma among odontocetes for basic and applied purposes. Although Western immunoblot analysis failed to detect $\beta$ $\beta$-NGF in belugas and Pacific white-sided and bottlenose dolphins as indicative of an OIF, the results are not conclusive that the beluga is not a facultative-induced ovulator. Future studies are required to address the apparent limitations of immuno-detection of NGF, especially if the post-translational form of $\beta$-NGF is in low abundance in the seminal plasma of odontocetes and, perhaps, other cetaceans.

\section{ACKNOWLEDGMENTS}

We thank the marine mammal specialists at SeaWorld for collecting the semen used for this research and Karen Steinman and laboratory staff of SeaWorld and Busch Gardens Species Preservation Laboratory for their assistance in processing the samples. This is a SeaWorld Parks and Entertainment technical contribution \#201804-F. This study was also supported by NYU NIEHS Center of Excellence Grant ES000260.

\section{REFERENCES}

Abou-Ahmed, M.M., M.S. El-Belely, S.T. Ismail, Y.R.M. ElBaghdad, and N.A. Hemeida. 1993. Influence of age and season on certain biochemical constituents of seminal plasma of Arabian horses. Animal Reproduction and Science 32:237-244.

Adams, G.P., and M.H. Ratto. 2013. Ovulation-inducing factor in seminal plasma: A review. Animal
Reproduction Science 136:148-156.

Adam,s G.P., M.H. Ratto, W. Huanca, and J. Singh. 2005. Ovulation-inducing factor in the seminal plasma of alpacas and llamas. Biology of Reproduction 73:452-457.

Allali $_{2}$ K.E., N.E. Bousmaki, H. Ainani, and V. Simonneaux. 2017. Effect of the Camelid's Seminal Plasma Ovulation-Inducing Factor/ $\beta$-NGF: A Kisspeptin Target Hypothesis. Frontiers in Veterinary Science 4:1-12.

Aloe, L., M.L. Rocco, P. Bianchi, and L. Manni. 2012. Nerve growth factor: from the early discoveries to the potential clinical use Journal of Translational Medicine 10:239.

Atkinson, S., C. Combelles, D. Vincent, P. Nachtigall, J. Pawloski, and M. Breese. 1999. Monitoring of progesterone in captive false killer whales (Pseudorca cressidens). General and Comparative Endocrinology 115:323-332.

Benirshcke, K., M.L. Johnson, and R.L. Benirschke. 1980. Is ovulation in dolphins Stenella longirostrus and Stenella attenuata, always copulation induced? Fishery Bulletin 78:507-528.

Bogle, O.A., M.H. Ratto, and G.P. Adams. 2011. Evidence for the conservation of biological activity of ovulationinducing factor in seminal plasma. Reproduction 142:277-283.

Bromfield, J. J. 2016. A role for seminal plasma in modulating pregnancy outcomes in domestic species. Reproduction 152:R223-R232.

Carvajal-Serna1, M., J.A. Cardozo, H. Grajales-Lombana1, J. A. Cebrián-Pérez and T. Muiño-Blanco. 2018. Sperm quality and seminal plasma proteins in three sheep breeds under high altitude and tropical conditions. Spanish Journal of Agricultural Research 16:1-13.

Combelles, C. 1995. Monitoring of progesterone in two species of captive small whales. MS Thesis, University of Hawaii. Manoa, Hawaii 132. pp

Chen, B.X., Z.X. Yuen, and G.W. Pan. 1985. Semen induced ovulation in the Bactrian camel (Camelus bactrianus). Journal of Reproduction and Fertility 73:335-339.

Drabovich, A.P., P. Saraon, K. Jarvi, and E.P. Diamandis. 2014. Seminal plasma as a diagnostic fluid for male reproductive system disorders. Nature Reviews Urology 11:278-288.

Druarta, X., J.P Rickard, S. Mactier, P.L. Kohnke, C.M. 
Kershaw-Young, R. Bathgate, Z. Gibb, B. Crossett, G. Tsikis, V. Labas, G. Harichaux, C.G. Grupen, and S.P. de Graaf. 2013. Proteomic characterization and cross species comparison of mammalian seminal plasma. Journal of Proteomics 91:13-22.

Domínguez, M.P., A. Falcinelli, F. Hozbor, E. Sánchez, A. Cesari, and R.H. Alberio. 2008. Seasonal variations in the composition of ram seminal plasma and its effect on frozen-thawed ram sperm. Theriogenology 69:564-73.

Fahnestock, M., G. Yu, B. Michalski., S. Mathew, A. Colquhoun, G.M. Ross., and M.D. Coughlin. 2004a. The nerve growth factor precursor proNGF exhibits neurotrophic activity but is less active than mature nerve growth factor. Journal Neurochemistry 89:581-592.

Fahnestock, M., G. Yu, and M.D. Coughlin. 2004b. ProNGF: a neurotrophic or an apoptotic molecule? Progress in Brain Research 146:101-110.

Harrison, R.J. 1977. Functional Anatomy of Marine Mammals. New York: Academic Press, 428.

Harrison, R.J., R.L. Brownell Jr, and R.C. Boice. 1972. Reproduction and gonadal appearances in some ondontocetes. In: Harrison R.J. (ed.). Functional Anatomy of Marine Mammals. London: Academic Press, 361-429.

Harrison, R.J., M.M. Bryden, D.A. McBrearty, and R.L. Brownell Jr. 1981. The ovaries and reproduction in Pontoporia blainvillei (Cetacea, Platanistidae). Journal of Zoology 93:563-580.

Harrison, R. J., and S.H. Ridgway. 1971. Gonadal activity in some bottlenose dolphins (Tursiops truncatus), Journal of Zoology 165:355-366.

Jochle, W. 1973. Coitus-induced ovulation. Contraception 7:523-564.

Jonakova, V., J. Jonak, and M. Ticha. 2010. Proteomics of male seminal plasma. In: Zhihua J., Troy L.O. (eds.). Reproductive genomics in domestic animals. Iowa: Wiley-Blackwell, 339-366.

Juyena, N.S. and C. Stelletta. 2012. Seminal plasma: An essential attribute of spermatozoa. Journal of Andrology 33:536-551.

Kauffman, A.S. and E.F. Rissman. 2006. Neuroendocrine Control of Mating-Induced Ovulation. In: Neill J.D. (Ed.). Knobil and Neill's Physiology of Reproduction, Third Edition, St. Louis, MO: Elsevier, Academic Press, 2283-2326.

Katoh-Semba, R., R. Semba, S. Kashiwamata, and K. Kato.
1989. Sex-Dependent and Sex-Independent Distribution of the $\beta$-Subunit of Nerve Growth Factor in the Central Nervous and Peripheral Tissues of Mice. Journal of Neurochemistry 52:1559-1565.

Katoh-Semba, R., R. Semba, H. Kato, M. Ueno, Y. Arakawa, and K. Kato. 1994. Regulation by androgen of levels of the beta subunit of nerve growth factor and its mRNA in selected regions of the mouse brain. Journal of Neurochemistry 62:2141-2147.

Kirby, V.L. and S.H. Ridgway. 1984. Hormonal evidence of spontaneous ovulation in captive dolphins (Tursiops truncatus and Delphinus delphis). In: W.F. Perrin, R.J., Brownell Jr., D.P. Demaster (Eds.). Reproduction in whales, dolphins and porpoises, Special Issue 6. Cambridge, UK: International Whaling Commission, 459-464.

Kleinenberg, S.E., A.V. Yablokov, B.M Belkovich, and M.N. Tarasevich. 1964. Beluga (Delphinapterus leucas): Investigation of the species. Moscow: Akademii Nauk SSSR. (Translation from original Russian by Israel Program for Scientific Translations, Jerusalem, 1969.)

Laemmli, U. K. 1970. Cleavage of structural proteins during the assembly of the head of bacteriophage T4. Nature 227: 680-685.

Mann T., Lutwak-Mann C. (1981) Male reproductive function and semen. In: Physiology, Biochemistry and Investigative Andrology. Berlin, Germany: Springer-Verlag, 495.

McGraw, L.A., S.S. Suarez, and M.F. Wolfner. 2015. On a matter of seminal importance: The emerging influence of seminal plasma components on fertility and future progeny. Bioessays 37:142147.

Mogielnicka-Brzozowska, M. and W. Kordan. 2011. Characteristics of selected seminal plasma proteins and their application in the improvement of the reproductive processes in mammals. Polish Journal of Veterinary Sciences 14:489-99.

O’Brien, J.K., K.J. Steinman, T. Schmitt, and T.R. Robeck. 2008. Semen collection, characterization and artificial insemination in the beluga (Delphinapterus leucas) using liquid-stored spermatozoa. Reproduction, Fertility and Development 20:770-783.

Pan, G., X. Zhao, S. Chen., S. Jiang, Y. Huang, Y. Zu., and H. Wang. 1992. The ovulation inducing effect of 
seminal plasma in the bactrian camel. In: Allen W.R., Higgins A.J., Mayhew I.G., Snow D., Wade J.F. (Eds.). Proc First International Camel Conference, 159-161.

Poiani, A. 2006. Complexity of seminal fluid: a review. Behav Ecol Sociobiol 60:289-310

Ratto, M.H., W. Huanca, J. Singh, and G.P. Adams. 2006. Comparison of the effect of ovulation-inducing factor (OIF) in the seminal plasma of llamas, alpacas, and bulls. Theriogenology 66:1102-1106.

Ratto, M.H., Y.A. Leducb, X.P. Valderrama, K.E. van Straatend, L.T.J. Delbaereb, R.A. Pierson, and G.P. Adams. 2012. The nerve of ovulation-inducing factor in semen. Proceedings of the National Academy of Sciences 109:15042-15047.

Robeck, T.R., K.J. Steinman, M. Yoshioka, E. Jensen, J.K. O’Brien, E. Katsumata, C. Gili, J.F. McBain, J. Sweeney, and S.L. Monfort. 2005. Estrous cycle characterization and artificial insemination using frozen-thawed spermatozoa in the bottlenose dolphin (Tursiops truncatus). Reproduction 129:659-674.

Robeck, T. R. and J.K. O'Brien. 2004. Effect of cryopreservation methods and precryopreservation storage on bottlenose dolphin (Tursiops truncatus) spermatozoa. Biology of Reproduction 70:1340-1348.

Robeck, T.R., A.L. Schneyer, J.F. McBain, L.M. Dalton, M.T. Walsh, N. Czekala, and D.C. Kraemer. 1993. Analysis of urinary immunoreactive steroid metabolites and gonadotropins for characterization of the estrous cycle, breeding period, and seasonal estrous activity of captive killer whales (Orcinus orca). Zoo Biology 12:173-188.

Robeck, T.R., K.J. Steinman, M. Greenwell, K. Ramirez, W. Van Bonn, M. Yoshioka, E. Katsumata, L. Dalton., S. Osborn, and J.K. O'Brien. 2009. Seasonality, estrous cycle characterization, estrus synchronization, semen cryopreservation, and artificial insemination in the Pacific white-sided dolphin (Lagenorhynchus obliquidens). Reproduction 138:391-405.

Rommel, S.A., D.A. Pabst, and W.A. McLellan. 2007.
Functional anatomy of the cetacean reproductive system,with comparisons to the domestic dog. In Miller D.L. (Ed.). Reproductive biology and phylogeny of cetacea: whales, dolphins and porpoises. Boca Raton, FL: CRC Press, 127-145.

Sawyer-Steffan, J.E., V.L. Kirby, and W.G. Gilmartin. 1983. Progesterone and estrogens in pregnant and nonpregnant dolphin (Tursiops truncatus) and the effects of induced ovulation. Biology of Reproduction 28:897-907.

Schroeder, J.P. 1990. Reproductive Aspects of Marine Mammals. In: Dierauf L.A., (Ed.). Handbook of Marine Mammal Medicine: Health, Disease and Rehabilitation. Boca Raton, FL: CRC Press, 353369.

Seidel, M.F., B.L. Wise, and N.E. Lane. 2013. Nerve growth factor: an update on the science and therapy. Osteoarthritis Cartilage 21:1223-1228.

Sharma, L., V. Pandey, R. Nigam, P. Singh, A. Saxena and D.K. Swain. 2014. Seasonal Variations in Seminal Plasma Proteins of Buffalo. Reproduction of Domestic Animals 49:387-391.

Steinman, K.J., J.K. O’Brien, S.L. Monfort, T.R. Robeck. 2012. Characterization of the estrous cycle in female beluga (Delphinapterus leucas) using urinary endocrine monitoring and transabdominal ultrasound: Evidence of facultative induced ovulation. General and Comparative Endocrinology 175:398-397.

Wiesmann, C. and A.M. de Vos. 2001. Nerve growth factor: structure and function. Cellular and Molecular Life Sciences CMLS 58:748-759.

Xu, Y.S., H.Y. Wang, G.Q. Zeng, G.T. Jiang, and H.Y. Gao. 1985. Hormone concentrations before and after semen-induced ovulation in the Bactrian camel (Camelus bactrianus). Journal of Reproduction and Fertility 74:341-346.

Yoshioka, M., E. Mohri, T. Tobayama, K. Aida, and I. Hanyu. 1986. Annual changes in serum reproductive hormone levels in captive female bottlenose dolphins. Bulletin of the Japanese Society of Scientific Fisheries 11:1939-1946. 
Publisher's note: EScience Press remains neutral with regard to jurisdictional claims in published maps and institutional affiliations.

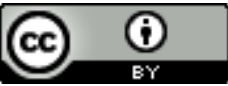

Open Access This article is licensed under a Creative Commons Attribution 4.0 International License, which permits use, sharing, adaptation, distribution and reproduction in any medium or format, as long as you give appropriate credit to the original author(s) and the source, provide a link to the Creative Commons license and indicate if changes were made. The images or other third-party material in this article are included in the article's Creative Commons license, unless indicated otherwise in a credit line to the material. If material is not included in the article's Creative Commons license and your intended use is not permitted by statutory regulation or exceeds the permitted use, you will need to obtain permission directly from the copyright holder. To view a copy of this license, visit http://creativecommons.org/licenses/by/4.0/.

(C) The Author(s) 2019 . 